\title{
Analysis of Sports Industry Development of Countryside
}

\author{
Renjian Liü, a, Ping Liü, b \\ ${ }^{1}$ Collegeof arts and sports, Sichuan agricultural university, Ya'an, Sichuan, China \\ ${ }^{2}$ Sichuan University of Science and Engineering, Zigong, Sichuan, China \\ 1Fengtt0828@163.com, ²editor@ifmsit.com
}

Keywords: Regional sports industry, Environment, Sichuan, New socialist countryside.

\begin{abstract}
In this paper, from the perspective of a new socialist countryside, the effects of external environment factors on the development of regional sports industry are explored by documentary analysis, comparative research, and the combination of regional economic theory. This article contains the following three aspects: Analyze the development pattern of sports industry by reviewing related literature; Macroscopically compare specific environmental factors of sports industry development around Sichuan province by actual data; Put forward suggestions, motivated by promoting balanced development of regional sports industry, on the development of sports industry in New socialist countryside of Sichuan province.
\end{abstract}

\section{Introduction}

In recent years, China's sports industry developed rapidly that makes it an important force which promotes social and economic progress in regions. In march.2013, the "Guiding Opinions of the State Council on Accelerating the Development of Sports Industry" presented that all levels of government should pay high attention to sports industry development, reinforce its presence in the sports industry development, reasonably planning and coordinating the development of sports industry in regions on the basis of socio-economy development status. The state level policy paper takes the strategy plan of regional sports industry. It offers macro guidance to regional sports industry. Regions are supposed to rely on local sport resources for developing characteristic sports industries, promoting competitiveness of sports industry, forming a pattern of complementation and mutual promotion.

\section{Regional Economy Development and Regional Sports Industry}

Regional economy is an entity which is territorially-wide and combined with economic factors and distributions. Economy development in regions is conditioned by natural conditions, socio-economic conditions and technical economic policies. Under certain conditions of productive forces development, region economy is conditioned by funding, technique and labor force [1].

Sports industry is a collection of organizations and departments who engaged in sports products manufacturing that meets the demand of watching sports games, sports shows and participating in physical exercises. Sports industry includes sports service industry, athletic products manufacturing and sales. In which, sports service industry covers sports fitness and entertainment industry and Competitive performance industry.

The proposing of regional sports industry is thought of new perspective on different region sports industry development programs, which inspire regions utilize its comparative advantages, which help regions establish industrial system with distinctive regional features that meet the demand of regional development and adaptable to both the regional resource and environment, the point is with practical significance on coordination development of sports industry and economy.

\section{The general development structure of sports industry in China}

China's sports industry is with an upward tendency. As a sports industrial late-developed country, sports industry is not listed in national economy calculation system, thus, there is no 
national dates could authoritatively reflect the current situation and structure of sports industry. Although started late, China's rapidly developing sports industry is getting close to it of developed countries. Through 30-years' growth, China is now the biggest country in sports products manufacturing. With increasing production value of sports industry during 2006 and 2011, the compounded annual growth rate (CAGR) reached 17.63\%. By 2011, the production value is 176 billion Yuan, reached more than $80 \%$ the share of sports industry, China is now the second biggest market of sports products after the US [2]. Although can't match the developed countries in production value, not rank in the ten major industries in China, sports industry is now becoming a new point of economic growth. Thus, there is still huge development space in the future. On the other hand, the Beijing Olympic Games in 2008, the Asian Games and the Universiade in 2011 greatly arouse human's interests in Sports.

Sports industry structure shows the eastern is characteristically stronger than the western. Currently, there is distinct unbalanced sports industry development among the east, the midland, and the west side, and also in East, Middle and West regions have difference which appears to like gradient development gap, it glows faster in economically developed areas than which economically developed areas [3]. Most notably in the polarization the three major economic zones, which is Beijing-Tianjin-Hebei economic zone that centered on Beijing, Yangtze River Delta economic zone that centered on Shanghai and the Pearl River Delta economic zone centered on Guangzhou, but for the midland, it is just in the infancy. Looking from the structure of sports industry, sports service distributed in higher economical developed province, Sports product manufacturing mainly distributed in coastal provinces in eastern.

Sports service development lags behind sports product manufacturing. Sports service is the core of sports industry, which is also called the basis, the developmental level of the core matches the level of its surroundings, meanwhile, the lag between sports service and sports product manufacturing occur in almost all provinces in China, the sales and product value of sports fitness, entertainment and sports watching that sports industry rely on account for only a fraction of the sports industry. That is far away from the sports product manufacturing and sales. This situation is taken by the transferring of sports product manufacturing to China, the eastern coastal province is now the main manufacturing base of sports industry.

Sports market system generally formed. Sports industry market is the carriers of sports products manufacturing, distributing and consuming. The blooming of sports industry rely on the sports market, a widely ranged, reasonably structured sports market system is the basis of a fast growing sports industry. With the deep reform of the economic system and the establishment of a socialist market economic system, sports market gradually structured by products, lotteries, competition etc. complemented by sports media, fitness, entertainment, intermediary, technical training, tourism, etc.

\section{Advices to sports industry in rural areas from a coordination perspective}

Developing sports industry with the opportunity of building a new socialist countryside. There are more than 900 million peasants in China, China's economy has been fully developed after three decades of reform and opening-up, and farmers' living standards have greatly improved, with the acceleration of the industrialization process, township urbanization and acceleration the pace of construction of small towns has become China's adjustment of industrial structure, economic development and an important strategic step [4].

In building a new socialist countryside guideline, especially in efforts to solve the problem of agriculture, rural areas and farmers, the rural economy greatly developed, people's quality of life has been significantly improved. Not only had the vast rural areas to solve the problem of food and clothing, and gradually achieve a comprehensive well-off standard of living. Feed and clothe these contemporary life is not the minimum requirements of farmers, in material life are fully met, these people needs spiritual life. Sport, as a culture and a high level of needs, will become part of their lives. Peasants' needs for sports increased the care and get involved in sports. Huge shortage of 
rural consumer groups and sports consumer market share in stark contrast. Lack of rural sports and sports consumer prices to the consumer market high sports consumption of residents brought a lot of inconvenience, this led to the devoice of sports market and actual needs. Incoordination lies between rural sports market and the rural population distribution. There is a contradiction between supply and demand.

Non- balanced way promoting balanced sports industry. Establish the city as the center of the city to promote rural development in the area of new socialist countryside sports industry development priorities and planning the layout based on comparative advantage and social development in different parts of the real economy, accordance with the "overall planning, highlighting the advantages of the integration of resources, industrial clustering" of ideas, construction of the regional distribution of the sports industry, formation of distinctive features, the entire areas, both inside and outside, the coordinated development of sports industry development pattern. "Sichuan Sports Industry Development Plan 2011-2020" and "Implementation Opinions on Accelerating the Development of Sichuan sports industry." By Sichuan province has a plan to Sichuan sports industry development, which concluded as one level, two zones, three areas, and multi district. Leading efforts to build Chengdu Sports Industry Development, Create specialty sports training, competitions and outdoor sports foster industrial belt industrial belt, Foster the south, the east and the north of a national physical fitness and sports and leisure industry zone, expand the Chengdu, Le Shan National Sporting Goods Manufacturing and Distribution Industry Park, Ganzi, A’ba mountaineering base industrial park, E’mei Qingcheng martial arts fitness regimen industrial park, industrial park Panxi Sunshine Sports.

According to local conditions, step by step, gradually develop national physical fitness and sports and leisure industries, take public sports facilities and various private fitness facilities as the carrier, and promote balanced regional development of the socialist new countryside sports industry.

Development of local sports industry and the construction of regional sports industry cooperation circle. Formation of urban and rural sports industry clusters are closely linked, urban sports circle through joint government, integration of resources and projects, forming a central area of the sports industry "growth pole", by "growth pole" to absorb the radiation to form the sports industry cluster. Sports industry development plan by coordinating between the cities, there are in circulation services, sports and other consumer division, there is collaboration, form an effective fixed chain. By the rule of market economy, expand rural sports market, expanding domestic sports demands. There are many traditional rural, with national characteristics of sports items, like Dragon and lion dance, the Younger, the Pot village dance etc. that popularized in Sichuan, promote these projects by take festival as a carrier, comprehensively improve sports performance and competitive nature, thus form a kind of entertainment and leisure projects featuring fitness and gradually formed in such sports as the main sports tourism industry.

Strengthen supervision of government investment, and attract private capital investment. Under the background of the new policy by "The State Council Decision on Reform of Investment System", "Sports Industry Development Program 1995-2010 and "The Sports Reform and Development Program" functions and role of government need to adjust and change, in the development process of sports industry, The role of government is to provide the greatest service, respect for market rules, formulate Investment and financing policies, broaden the funding sources, increase investment and financing support, encourage and guide non-public economic entities participating in sports resources configuring, invest in the production and operation of the sports industry, formulate policies that encourage private and foreign capital to develop the sports industry, to change the private-based pattern. Improve sports lottery market management system, soundly sports lottery issuance, sale, and use of monitoring mechanisms lottery, improving efficiency in the use of sports lottery, formulate policies that encourage social forces to develop sports foundation donated established[5].

In terms of performance of its functions, governments need to encourage market competition, combat local protectionism, establish invest and tax system that suitable for sports industry 
clustered developed, so that the flow of resources to the sports industry has comparative advantage. Under a perfect market economic system, make investments intentions related industries and enterprises, private capital and foreign capital have bigger space to match their values.

\section{Conclusion}

In the future, with the continuous development of the tertiary industry, emerging industries and modern services, which sports industry included, will further enhance the economic value. Hence, the key of sports industry development is to create a better environment for the development of the sports industry and market. There is indeed a large gap between new socialist rural sports industry development and economic and social environment, this article hold the opinion that sports industry development varying degrees affected by economic development, income and changes in consumer attitudes, social capital investing, government policy guiding, etc.

\section{References}

[1] The development of Chinese sports industry report, Beijing, people's sport publishing house, 2006.

[2] G.M. Zhang and Y. Wang. The basic position of regional sports industry in China, based on the perspective of regional coordinated development of sports industry, Shenyang sports college journal, 2011, 30 (3) : 3-6.

[3] Y.J. Tong and H.F. Cong. The eastern part of our country sports industry development in social economy "outside environment" regional comparative advantage and the choice of the ways of development. Journal of Chinese sports science and technology, 2002, 38 (11) : 325.

[4] H.J. Liu. Theory of sports industry environment. Journal of sport culture Tribune, 2006, (5):14-16.

[5] J. Min, F. Lu and C.B. Xu. The methodology of the operating environment of the sports industry market analysis Journal of Chengdu sports institute, 2003, 29 (2): 6-10. 